\title{
Synthesis of sulfonamide derivatives containing the structural fragment of pyrazol-1-yl-pyridazine
}

\author{
(C) Ljudmila A. Komshina, ${ }^{1+}$ Valentina V. Martazova ${ }^{1}$, Mikhail K. Korsakov, ${ }^{1,2} *$ \\ Irina K. Proskurina ${ }^{1}$, Alexandr D. Kotov ${ }^{1}$ and Elena B. Karavaeva ${ }^{2}$ \\ ${ }^{1}$ Department Chemistry, Theories and Methods of teaching Chemistry. Yaroslavl State \\ Pedagogical University Named after K.D. Ushinsky. Respudlikanskaja St., 108. \\ Yaroslavl, 150000. Russia.Phone: +7 (8452) 73-15-29. E-mail: komshinala@mail.ru \\ ${ }^{2}$ Russian State University Named after A.N. Kosygina (Technologies. Design. Art). \\ Sadovnicheskaya St., 33, bldg.1. Moscow, 117997. Russia.
}

\begin{abstract}
*Supervising author; ${ }^{+}$Corresponding author
Keywords: pyrazoles, pyridazines, sulfonylchlorination, sulfonylamides.
\end{abstract}

\begin{abstract}
Sulfonamide derivatives of heterocyclic compounds are promising targets for the search for new substances with specific biological activity. They are widely used as inhibitors of human carbonic anhydrases involved in the implementation of various biochemical processes. The presence of several heterocyclic systems in the structure of sulfonamides significantly increases the ability to bind to active sites of carbonic anhydrases and inhibit their activity. Therefore, the development of approaches to the preparation of sulfonamides of polynuclear heterocyclic compounds is of great scientific interest. This article proposes a multistage scheme for the synthesis and characterization of new sulfonamide derivatives of 1-aryl-6-pyrazol1-yl-pyridazines. The synthesis of substituted pyrazol-1-yl-pyridazines was carried out by sequential conversion of arylpyridazinones by refluxing in phosphorus oxychloride to 3-chloro-6-arylpyridazines, at the next stage as a result of the nucleophilic substitution of activated chlorine in the pyridazine ring with hydrazine, arylpyridazines were obtained with the reaction Refluxing in butanol, the target compounds with a 3,5-dimethylpyrazole structural fragment were synthesized. The study of the regularities of the course of sulfonylchlorination of 1-aryl-6-pyrazole-1yl-pyridazines made it possible to establish the effect of the substrate structure on the direction of the process and the selectivity of the reaction, as well as on the possibility of the formation of disubstitution products. The corresponding disulfonyl chloride was obtained only in the case of sulfonylchlorination of 1-(4-methoxyphenylpyridazin-3-yl)-3,5-dimethyl-1 $H$-pyrazole at $100{ }^{\circ} \mathrm{C}$ for $10 \mathrm{~h}$. In this case, the hydrogen atoms in position 3 of the benzene ring and position 4 of the pyrazole ring. In all other cases, monosubstitution products were obtained at the 4-position of the pyrazole ring. This is evidenced by the data of ${ }^{1} \mathrm{H}$ NMR spectroscopy. On the basis of the obtained sulfonyl chlorides, the corresponding mono- and disulfonamides were synthesized. Convincing proof of the structure of all the obtained compounds has been carried out by a combination of mass spectrometry and NMR spectroscopy data.
\end{abstract}

\section{References}

[1] L.A. Shumilova, M.K. Korsakov, M.V. Dorogov, etc. Synthesis of novel bifunctional bi-nuclear isoxazoles containing molecular systems. Yaroslavl Pedagogical Bulletin. (Natural Sciences). 2013. Vol.III. No.4. P.231-235. (russian)

[2] E.V. Semenichev, M.K. Korsakov, and Yu.V. Novozhilov. New transformation of 3-methyl-4-nitro-5vinylisoxazole to pyridinone. Butlerov Communications. 2011. Vol.24. No.3. P.45-48. ROI-jbc-02/11-24$1-45$

[3] N. Kurumurthy, R. Sambasiva, K. Santhosh, Veeraswamy, S. Kotamraju, K. Thelakkat. Synthesis of novel 5-substituted isoxazole-3-carboxamide derivatives and cytotoxicity studies on lung cancer cell line. Indian Journal of Chemistry - Section B Organic and Medicinal Chemistry. 2012. Vol.51. No.9. P.13691375.

[4] L.A. Komshina, V.V. Martazova, I.K. Proskurina, M.K. Korsakov, and A.D. Kotov. Synthesis of 3arylisoxazoles and their sulfamide derivatives. Butlerov Communications. 2020. Vol.63. No.9. P.10-18. DOI: $10.37952 /$ ROI-jbc-01/20-63-9-10 